\title{
ANALISIS MANAJEMEN ARUS KAS TERKAIT KEBIJAKAN UANG KULIAH TUNGGAL DAN BIAYA KULIAH TUNGGAL SEKOLAH TINGGI AGAMA ISLAM NEGERI DI SULAWESI SELATAN
}

\author{
Fahri Abdullah \\ Institut Agama Islam Negeri Bone, Indonesia \\ e-mail: fahri.abdullah@gmail.com
}

\begin{abstract}
This research was conducted with the aim to; analyzing cash flow management, reviewing the acceptance of the first one-year regular SPP S1 for STAIN students and the first year until the fourth year before and after the policy of Single Tuition and Single Tuition Fee (UKT-BKT) at the State Islamic High School in South Sulawesi. This research uses descriptive analysis and statistical test, statistic test on acceptance and use before and after UKT-BKT, done with t test for paired sample with SPSS (Statistical Package for the social science) with $90 \%$ confidence level (significant level $\alpha=0.05$. With the aim of knowing whether there is a real difference in the acceptance of regular S1 SPP before and after the policy of UKT and BKT. The results of this study indicate that there is no significant mean difference between acceptance before and after UKT in the variables of use so as to be able to maintain the liquidity of cash flows at the two institutions. While the ratio analysis test shows the agency's ability to finalize short-term liabilities for current ratio, And for quick ratio shows the ability of both institutions to pay off current debt. In the Second Cash Ratio the agency can settle operational payments and programmed activities.Based on the analysis of cash ratio before and after UKT BKT in both institutions have Liquid cash means Both universities are able to pay off short-term debt and can run the program even though in 2015 until 2017 there is an outstanding debt but can be paid because the initial cash from KPPN as payment in advance.
\end{abstract}

Keywords: Cash Flow Management, Single Tuition Policy, Single Lecture Fee.

\section{Pendahuluan}

Pendidikan mempunyai peran penting dalam meningkatkan kualitas sumber daya manusia. Pendidikan sangat berperan dalam membentuk baik atau buruknya pribadi manusia menurut ukuran normatif. Menyadari akan hal tersebut, pemerintah sangat serius menangani bidang pendidikan, sebab dengan sistem pendidikan yang baik diharapkan muncul generasi penerus bangsa yang berkualitas dan mampu menyesuaikan diri untuk hidup bermasyarakat, berbangsa dan bernegara. Undang-undang Nomor 20 tahun 2003 tentang Sistem Pendidikan Nasional dijelaskan bahwa pendidikan nasional berfungsi mengembangkan kemampuan dan membentuk watak serta peradaban bangsa yang bermartabat dalam rangka mencerdaskan kehidupan bangsa, bertujuan untuk berkembangnya potensi peserta didik agar menjadi manusia beriman dan bertaqwa kepada Tuhan Yang Maha Esa, berakhlak mulia, sehat, 
berilmu, cakap, kreatif, mandiri, dan menjadi warga negara yang demokratis serta bertanggung jawab. ${ }^{1}$

Usaha yang dilakukan oleh Pemerintah untuk menindaklanjuti hal tersebut lahirlah Peraturan Menteri Pendidikan dan Kebudayaan Republik Indonesia No. 55 Tahun 2013 tentang Biaya Kuliah Tunggal (BKT) dan Uang Kuliah Tunggal (UKT) pada seluruh Perguruan Tinggi Negeri di Indonesia, dimana Biaya Kuliah Tunggal merupakan keseluruhan biaya operasional per mahasiswa per semester pada program studi di Perguruan Tinggi Negeri. Biaya Kuliah Tunggal digunakan sebagai dasar penetapan biaya yang dibebankan kepada mahasiswa, masyarakat dan pemerintah. Sedangkan Uang Kuliah Tunggal ditetapkan berdasarkan Biaya Kuliah Tunggal dikurangi biaya yang ditanggung oleh Pemerintah.

Penyelenggaran pendidikan membutuhkan dana serta pengelolaan yang tepat. Sumber pendapatan Sekolah Tinggi Agama Islam Negeri di Sulawesi Selatan Tahun 2012 sampai dengan tahun 2014 berasal dari Sumbangan Penyelenggaraan Pendidikan (SPP) dengan menentukan komponen biaya kuliah yang harus dibayarkan oleh Mahasiswa, dimana terdapat penerimaan dari tahun 2012 sampai dengan 2014 rata-rata pendapatan sebesar 15\% per tahun dari total Anggaran dengan subsidi pemerintah $85 \%$ pada sekolah Tinggi Agama Islam Negeri (STAIN) di Sulawesi Selatan. Sementara setelah Uang Kuliah Tunggal dan Biaya Kuliah Tunggal penerimaan dari tahun 2015 sampai dengan 2017 rata-rata $14 \%$ pertahun dengan subsidi pemerintah $86 \%$ per tahun dimana penetapan UKT-BKT berdasarkan penetapan standar pembiayaan uang kuliah oleh pemerintah dengan memperhatikan keterjangkauan (sumber data unit PNBP dan perencana Anggaran per januari 2017)

Kas ini merupakan aktiva yang tidak dapat menghasilkan "laba", dalam arti tidak bisa untuk mendapatkan laba secara langsung dalam operasionalnya. Oleh karena itu perlu dilakukan usaha pengelolaan manajemen kas yang efektif dan efisien sehingga pemanfaatan kas tersebut dapat optimal. Kas diperlukan untuk operasi lembaga sehari-hari (dalam bentuk modal kerja) maupun pembelian aktiva tetap. ${ }^{2}$

Berdasarkan dari uraian latar belakang diatas, maka penulis merasa tertarik untuk mengkaji lebih jauh mengenai manajemen arus kas di Sekolah Tinggi Agama Islam Negeri (STAIN) di Sulawesi Selatan setelah diberlakukannya Uang Kuliah Tunggal serta implikasinya terhadap kebijakan program kegiatan lembaga pada Sekolah Tinggi Agama Islam Negeri di Sulawesi Selatan.

\section{Teori Manajemen}

George R. Terry, mengatakan bahwa manajemen merupakan proses yang khas terdiri dari tindakan-tindakan : perencanaan, pengorganisasian, menggerakkan dan pengawasan yang dialkukan untuk menentukan serta mencapai sasaran-sasaran yang telah ditetapkan melalui pemanfaatan sumber daya manusia serta sumber-sumber lain. ${ }^{3}$

\footnotetext{
${ }^{1}$ Team Redaksi Sinar Grafika, Undang-Undang Sisdiknas (Sistem Pendidikan Nasional) 2003 (UU. RI No. 20 Th 2003) Cetakan Pertama, Jakarta; Sinar Grafika) h.102

${ }^{2}$ Martono, SU dan Agus Marjito, Manajemen Keuangan, (Cet. IV; Yogyakarta, 2017), h. 112

${ }^{3}$ George Terry, Dasar-Dasar Manajemen, (Cetakan ke.14; Jakarta; 2018), h.169
} 
Dari beberapa pengertian di atas, dapat kita simpulkan bahwa manajemen adalah seni dalam mengatur sistem baik orang dan perangkat lain agar dapat berjalan dan bekerja sesuai dengan ketentuan dan tujuan entitas yang terdiri dari berbagai aktivitas sebagaimana disebutkan oleh George Terry.

\section{Kas}

Kas dan setara kas menurut PSAK No.2 (IAI, 2012:22) "Kas terdiri dari saldo kas (cash on hand) dan rekening giro. Setara kas (cash equivalent) adalah investasi yang sifatnya sangat liquid, berjangka pendek dan dengan cepat dapat dijadikan sebagai kas dalam jumlah tertentu tanpa menghadapai risiko perubahan nilai yang signifikan." Kas merupakan komponen asset (asset) lancar yang paling likuid di dalam neraca, karena kas sering mengalami mutasi atau perpindahan dan hampir semua transaksi yang terjadi dalam perusahaan akan mempengaruhi posisi kas. ${ }^{4}$

\section{Arus Kas}

Laporan arus kas (statement of cash flow atau cash flow) adalah laporan yang menyajikan ikhtisar terinci mengenai semua arus kas masuk dan arus kas keluar, atau sumber dan penggunaan kas selama suatu periode ( IAI : 2007) ${ }^{5}$. Arus kas, dikategorikan atas tiga unsur arus kas yaitu, Aru Kas Operasi, Arus Kas Invesasi dan Arus Kas Pendanaan.

\section{Analisis Laporan Arus Kas Dalam Menilai Kinerja Lembaga}

Analisis Laporan arus kas merupakan analisis finansial yang sangat penting bagi seorang manajer keuangan suatu perusahaan disamping alat-alat finansial lainnya. Dengan melakukan analisis laporan arus kas, manajer keuangan dapat melaksanakan salah satu fungsinya yaitu fungsi perencanaan. Analisis laporan arus kas ini menggunakan komponen dalam laporan arus kas dan komponen neraca dan laporan laba rugi sebagai informasi dalam analisis rasio.

Teori likuiditas adalah berhubungan dengan masalah kemampuan suatu perusahaan untuk memenuhi kewajiban finansialnya yang segera harus dipenuhi. Berdasarkan beberapa pendapat diatas dapat dikatakan bahwa pengertian likuiditas adalah kemampuan suatu perusahaan untuk memenuhi atau membayar kewajiban keuangan jangka pendek yang harus segera dipenuhi. Rasio likuiditas terdiri atas Current Ratio (Rasio Lancar), merupakan perbandingan antara aktiva lancar (current ratio) dengan hutang lancar (current liabilities). Menentukan current ratio dianggap baik sekitar 200\% tetapi hal ini tidak menjadi standar khusus untuk menentukan ratio yang paling baik. Quick Ratio (Rasio Cepat), alat ukur yang lebih akurat untuk mengukur tingkat likuiditas perusahaan adalah quick ratio (acid test ratio). Quick Ratio menfokuskan komponen aktiva lancar yang lebih liquid yaitu kas, surat berharga, dan piutang dihubungkan dengan hutang lancar, atau hutang jangka pendek. Rasio Kas (Rasio Aset Tunai) adalah rasio yang digunakan untuk membandingkan total kas (tunai) dan

\footnotetext{
${ }^{4}$ Agus Sarton, Manajemen Keuangan Teori dan Aplikasi, (Edisi Ketiga, BPFE, Yogykarta 2010) h.216

5 Agus Sarton, 2010, Manajemen Keuangan Teori dan Aplikasi, (Edisi Ketiga; Penerbit BPFE, Yogykarta 2010) h. 269
} 
setara kas perusahaan dengan kewajiban lancarnya. Rasio kas yang terlalu tinggi dapat menunjukkan penggunaan aset yang tidak maksimal bagi perusahaan karena memegang uang tunai yang terlalu banyak di neraca keuangannya. (Rasio kas untuk membayar hutang \% kewajibang lancarnya artinya hanya memiliki kas berapa kali untuk membayar hutangnya). ${ }^{6}$

\section{Uang Kuliah Tunggal dan Biaya Kuliah Tunggal (UKT-BKT)}

UKT adalah singkatan dari Uang Kuliah Tunggal, yang merupakan nama dari sebuah sistem pembayaran yang saat ini berlaku di seluruh perguruan Tinggi Negeri, Ketentuan ini berdasarkan Permendikbud No. 55 Tahun 2013, yakni setiap mahasiswa hanya membayar satu komponen saja yang di sebut dengan UKT.

Diberlakukannya UKT merupakan sistem biaya kuliah baru di Indonesia, adanya UKT meniadakan sumbangan pembinaan pendidikan (SPP) dan Uang pangkal, UKT juga hadir dengan syarat pembayaran gedung, almamater, KKN, wisuda terpisah dan pungutan liar lainnya, karena sistem ini menjadi akumulasi dari seluruh tunggukan kuliah akan dipaketkan dalam satu pembayaran yang disebut UKT. Adapun prinsip UKT subisidi silang antara yang kaya menopang yang miskin, melalui hitungan BOPTN-BKT = UKT merupakan rumus dasar akan UKT yang selanjutnya. BOPTN atau Bantuan Operasional Perguruan Tinggi Negeri merupakan bentuk bantuan pemerintah pusat untuk menutupi BKT atau Biaya Kuliah Tunggal, sedang BKT merupakan kalkulasi kebutuhan operasional perguruan TInggi dari bantuan dan total kebutuhan perguruan tinggi tidak bisa tertutupi BKT oleh BOPTN inilah yang akan dibebankan kepada mahasiswa yang disebut UKT tadi. ${ }^{7}$

\section{Dalil UKT}

Uang Kuliah Tunggal merupakan sebagian biaya kuliah tunggal yang dibayarkan oleh Mahasiswa, sehingga pemerintah memberikan dana BOPTN untuk menutupi biaya kekurangan operasional pendidikan. Namun BOPTN tidak ada kesesuian dan kelayakan anggaran yang didapatkan untuk membiayai selisih kekurangan operasional sehingga mengakibatkan lembaga tidak berjalan efektif dan efisien. Berdasarkan Peraturan Menteri Pendidikan dan Kebudayaan Republik Indonesia Nomor 55 Tahun 2013 tentang, Biaya Kuliah Tunggal (BKT) dan Uang Kuliah Tunggal (UKT) pada Perguruan Tinggi Negeri dilingkungan Kementerian Pendidikan dan Kebudayaan.

\section{Jenis-Jenis UKT}

Pertama, UKT untuk mahasiswa yang tidak mampu membayar biaya kuliah, pada UKT yang pertama ini, mahasiswa akan dibebaskan 100 persen dari biaya perkuliahan. Kedua, UKT untuk kelompok mahasiswa kurang mampu. Ketiga adalah UKT untuk mahasiswa yang mampu membayar biaya perkuliahan. ${ }^{8}$

\footnotetext{
${ }^{6}$ Brighman Houston, Dasar-Dasar manajemen Keuangan, (Edisi Ke-11; Penerbit Salemba Empat; Jakarta, 2010) h. 368

7 https://www.finansialku.com/biaya-kuliah-tunggal-dan-uang-kuliah-tunggal/jam.14.25 wita tanggal. 04 April 2018

8 https://www.cermati.com/artikel/empat-jenis-pembagian-biaya-kuliah-di-tahun-2016-ini-rinciannya jam.14.45 Wita tanggal 04 April 2018
} 
Nasir menyatakan bahwa kemampuan financial setiap peserta didik di bangku perguruan tinggi memang berbeda-beda. Maka dari itu, penerapan UKT pun memang harus disesuaikan dengan kemampuan finansial masing-masing mahasiswa tersebut. Dari sini, biaya kuliah tidak boleh dipukul rata dan pembebasan biaya UKT tetap harus diterapkan hanya bagi yang mampu. Kalau diterapkan pada semua mahasiswa maka biaya operasional kampus bisa tidak tertutupi. (Kebijakan Menteri Riset Tekhnologi dan Pendidikan Tinggi) (Mohammad Nasir, (2015) ${ }^{9}$

\section{Kerangka Konseptual}

Penyelenggaran pendidikan membutuhkan dana serta pengelolaan yang tepat. Sumber pendapatan Sekolah Tinggi Agama Islam Negeri di Sulawesi Selatan Tahun 2012 sampai dengan tahun 2014 berasal dari Sumbangan Penyelenggaraan Pendidikan (SPP) dengan menentukan komponen biaya kuliah yang harus dibayarkan oleh Mahasiswa, dimana terdapat penerimaan dari tahun 2012 sampai dengan 2014 rata-rata $15 \%$ dari dari masyarakat dalam hal ini mahasiswa setahun sebagai PNBP (Pendapatan Negara Bukan Pajak) dengan subsidi pemerintah 85\% untuk APBN (Anggaran Pendapatan Belanja Negara), sementara setelah Uang Kuliah Tunggal dan Biaya Kuliah Tunggal rata-rata penerimaan kas dari tahun 2015 sampai dengan 2017 adalah $12 \%$ dari mahasiswa sebagai PNBP dengan subsidi pemerintah $88 \%$ per tahun dimana penetapan UKT-BKT berdasarkan penetapan standar pembiayaan uang kuliah oleh pemerintah dengan memperhatikan keterjangkauan (sumber data unit PNBP dan perencana Anggaran per januari 2017) Sekolah Tinggi Agama Islam Negeri di Sulawesi Selatan.

Tabel 1

Tabel Biaya Pendidikan Sebelum

UKT STAIN Watampone

\begin{tabular}{|c|c|c|c|c|c|c|c|c|}
\hline No & ANUN & JENts PNGP & $\begin{array}{c}\text { TNUN } 2012 \\
\text { (PQ) }\end{array}$ & PROSERTASE & $\begin{array}{c}\text { TNume } 2013 \\
\text { (PQ) }\end{array}$ & prosentase & $\begin{array}{c}\text { TNenN } 2014 \\
\text { (Rp) }\end{array}$ & PROSEntASE \\
\hline 1 & ensil & Bus Penyutorm SPP & $2.613,400,000$ & 9379 & $2917,200,000$ & $90: 4$ & 3.967 .050 .000 & 2326 \\
\hline 2 & 423512 & Pendatarm uaBa / Wisuda & $61,725.000$ & 222 & $e 9.900 .000$ & 2.16 & $124,400,000$ & 2.91 \\
\hline 3 & $\operatorname{sen} 1$ & Jena Gro & 500,000 & 000 & - & - & - & - \\
\hline 4 & 420510 & Kantu Prorpubataan & $25,250,000$ & 120 & $43,500,000$ & 134 & . & - \\
\hline s & casts & Internet & $2,500,000$ & $\theta \infty$ & $2,450,000$ & $a c e$ & $32,175,000$ & ans \\
\hline \multirow[t]{2}{*}{6} & 423513 & Penyotoran Prastikum & $73,200,000$ & 263 & $200,100,000$ & 628 & $130,800,000$ & 3.06 \\
\hline & & JUMLAH & $2.786 .575,000$ & & $3256,150,000$ & & $4.274,400,000$ & 10000 \\
\hline
\end{tabular}

Sumber : Olahan Data Perencana dan PNBP STAIN Watampone untuk SPP

Komponen biaya Uang Kuliah Tunggal disajikan pada Tabel 2, yang dibayarkan berdasarkan kelompok pembayaran sesuai dengan peraturan Pemerintah tentang pungutan PNBP pada UKT-BKT berikut tabel olahan pendapatan UKT-BKT pada Sekolah Tinggi Agama Islam Negeri Watampone sebagai berikut :

9 http://www.kopertis12.or.id/2015/03/22/menteri-nasir-kaji-kebijakan-ukt-dan-akreditasi-perguruantinggi.html. Jam 15.20 Wita tanggal 04 April 2018 
Tabel 2

Biaya Pendidikan Setelah Uang Kuliah Tunggal

Sumber : Olahan Data Perencana dan PNBP STAIN Watampone untuk SPP

\begin{tabular}{|c|c|c|c|c|c|c|c|c|}
\hline No. & AKUN & JENS PNBP & $\begin{array}{c}\text { TAHUN } 2015 \\
\text { (Rp) }\end{array}$ & PROSENTASE & $\begin{array}{c}\text { TAYUN } 2016 \\
\text { (RP) }\end{array}$ & PROSENTASE & $\begin{array}{c}\text { TAHUN } 2017 \\
(\mathrm{Rp})\end{array}$ & PROSENTASE \\
\hline 1 & $\$ 23511$ & Buis Panyutoran SPP 600 & $2,474,100,000$ & 39 & $1,662.275,000$ & 18 & $939,000,000$ & b \\
\hline 2 & 423511 & Buss Panyetoran UKT & $3,533,550,000$ & 55 & $5,889.425,000$ & 65 & $9,121,725,000$ & 78 \\
\hline 3 & 423511 & B. Ponyutorin Spp Pasca 25 & \multirow[t]{2}{*}{$415,000,000$} & \multirow[t]{2}{*}{6} & $982,500,000$ & 11 & $1,075,000,000$ & 9 \\
\hline 4 & 423519 & Panteagatan Lainiryi & & & $467,400,000$ & 5.19 & $573,750,000$ & 4.90 \\
\hline & & & $6.422 .650,000$ & 100 & $9.001,600,000$ & & $11,709,475,000$ & 100 \\
\hline
\end{tabular}

Begitu juga pada pada STAIN Pare-Pare ini berasal dari sumbangan penyelenggaraan pendidikan (SPP) dan Non SPP serta subsidi pemerintah. SPP dan Non SPP dari tahun 2012 sampai dengan 2015 berasal dari mahasiswa (masyarkat) seperti tabel berikut

Tabel 3

Biaya Pendidikan Sebelum Uang Kuliah Tunggal

\begin{tabular}{|c|c|c|c|c|c|c|c|c|}
\hline Na & ACUN & JENAS PUiBP & $\begin{array}{c}\text { TNUUN } 2012 \\
(\mathrm{RQ})\end{array}$ & PROSENTASE & $\begin{array}{c}\text { TAtuliz2013 } \\
\text { (Re) }\end{array}$ & PROSENTASE & $\begin{array}{c}\text { TNHUN } 2014 \\
\text { (RP) }\end{array}$ & PROSENTASE \\
\hline 1 & 232511 & Buditi Penvetoran SPp & $2 \pi 2.600,000$ & 9302 & $2,305,382,000$ & 0230 & $3002,100,000$ & 9554 \\
\hline 2 & 423512 & Pendritran MheA / Msuda & 41,2200000 & 130 & $41,040,000$ & 150 & $81,030,000$ & 2.15 \\
\hline 3 & 123221 & Lasa Gro & 500000 & 0.92 & . & . & . & . \\
\hline 4 & 123510 & Katu Peppustakan & $70,400,000$ & 266 & $72,400,000$ & 200 & . & . \\
\hline 5 & 423510 & Iminmet & 1,500000 & 0.05 & $1,460,000$ & 0.05 & 30000,000 & $00 \mathrm{a}$ \\
\hline \multirow[t]{2}{*}{6} & 423513 & Penvetoran Prahthum & 95,300000 & 2000 & $04,100,000$ & 325 & $84,000,000$ & 223 \\
\hline & & JUMLAH & 2.9006000000 & & $2,504,382,000$ & & $3,770,360,000$ & 10000 \\
\hline
\end{tabular}

Sumber data olahan dari Perencana dan Pengelola PNBP STAIN Pare-Pare

Komponen biaya Uang Kuliah Tunggal disajikan pada Tabel 3, yang dibayarkan berdasarkan kelompok pembayaran sesuai dengan peraturan Pemerintah tentang pungutan PNBP pada UKT-BKT berikut tabel olahan pendapatan UKT-BKT pada Sekolah Tinggi Agama Islam Negeri Watampone dan Pare-Pare sebagai berikut :

Tabel 4

Biaya Pendidikan Setelah Uang Kuiah Tunggal STAIN Pare-Pare

Sumber : Olahan Data Perencana dan PNBP STAIN Watampone untuk SPP

\begin{tabular}{|c|c|c|c|c|c|c|c|c|}
\hline No. & AKUN & SEUSPIGP & $\begin{array}{c}\text { TAHUN } 2015 \\
(R p)\end{array}$ & Prosentase & $\begin{array}{c}\text { TAHJiH } 20016 \\
\text { (Rp) }\end{array}$ & PROSEMTASE & $\begin{array}{c}\text { TAHAN } 2017 \\
\text { (RP) }\end{array}$ & PROSENTASE \\
\hline$t$ & 423511 & Bukt Penyedoran SPP 600 & $1,247,500,000$ & 23 & $1,652,140,000$ & 22 & 632052000 & 6 \\
\hline 2 & 422511 & Bukt Penyetoran UKT & 3,7at, 506,000 & 68 & $5,273,306,000$ & $7 t$ & $9.561,206,000$ & 90 \\
\hline 3 & 123511 & A Penyetoran SPP Pasca 25 t & \multirow[t]{2}{*}{$415,000,000$} & \multirow[t]{2}{*}{8} & \multirow[t]{2}{*}{$426,000,000$} & 7 & \multirow[t]{2}{*}{$3 a t, 000,000$} & 4 \\
\hline 4 & 223519 & Pendapatan Lainnya & & & & $=$ & & - \\
\hline & & & 5.449005000 & 100 & $7,415,440,000$ & & $10,564,260,000$ & 100 \\
\hline
\end{tabular}


Terkait dengan hal tersebut dilakukan penelitian dengan tujuan menganalisis arus kas di kedua lembaga tersebut, serta menganalisis perbedaan penerimaan SPP S1 untuk tahun 2012 sampai dengan 2014 dan setelah Uang Kuliah Tunggal dan Biaya Kuliah Tunggal tahun 2015 sampai taun 2017 (sebelum dan sesudah UKT-BKT) dalam merumuskan kebijakan yang berimplikasi pada pengambilan keputusan untuk penyerapan Anggaran yang proporsional.

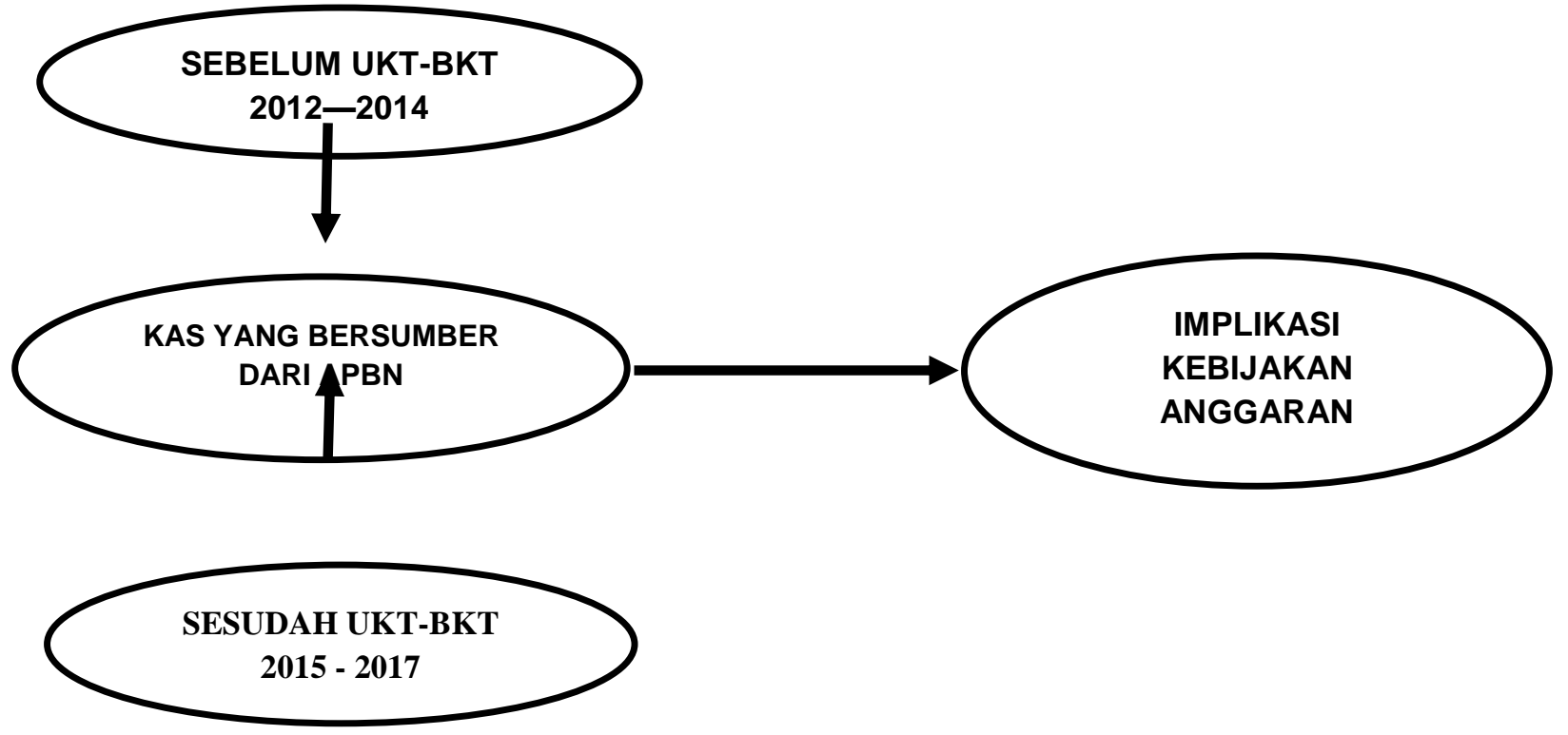

\section{Hipotesis}

Penelitian ini menggunakan uji analisis dengan hipotesis menurut penulis adalah :

1. Uang Kuliah Tunggal dan Biaya Kuliah Tunggal dapat mempengaruhi arus kas lembaga di Sekolah Tinggi Agama Islam Negeri di Sulawesi Selatan.

2. Manajemen kas dalam hal penerimaan tidak memenuhi kebutuhan pengeluaran yang berimplikasi terhadap kebijakan program dan kegiatan yang disebabkan perbandingan kemampuan pendapatan dan anggaran yang bersumber dari Rupiah Murni (RM) dan PNBP tidak terpenuhi secara maksimal sehingga efesiensi dan efektifitas lembaga tidak berjalan sesuai tujuan lembaga.

\section{Pendekatan Penelitian}

Pendekatan dalam penelitian ini melakukan pendekatan kualitatif. Fokus penelitian diidentifikasikan sebagai proses kerja yang berlangsung secara lisan dan tertulis yakni mengenai sejarah singkat dan informasi lainnya dari berbagai sumber seperti studi pustaka atas literatur serta jurnal yang berkaitan dengan penelitian ini. ${ }^{10}$ Obyek penelititan adalah SPP sebelum dan sesudah kebijakan UKT yang disesuaikan peraturan perundang-undangan 
tentang pemungutan PNBP dilingkup pendidikan Islam. Data yang digunakan dalam penelitian ini adalah data primer dan data sekunder. Data primer diperoleh dengan teknik observasi langsung ke lokasi dan obyek penelitian, disertai dengan wawancara sementara data sekunder berupa Laporan Perencanaan Anggaran, Laporan keuangan, Data Pegawai, Data Mahasiswa, Data Penggunaan pada SPP 3 (tiga) tahun yaitu tahun 2012 sampai dengan tahun 2014 dan penggunaan setelah UKT-BKT 3 (Tiga) Tahun Terakhir audited tahun 2015-2017, dan data lainnya berupa buku, jurnal, penelitian terdahulu dan sumber lain yang berhubungan dengan masalah penelitian. Penelitian ini juga menggunakan metode deskriptif serta pengujian statistika Pengujian statistika terhadap penerimaan SPP S1 reguler sebelum dan sesudah UKT dilakukan dengan uji t untuk sampel berpasangan dengan bantuan SPSS (Statical Package for the Social Science) Ver 14 dengan taraf kepercayaannya 95\% (taraf signifikan $\alpha=0.05$ ). Uji t bertujuan untuk mengetahui ada tidaknya perbedaan nyata dalam hal penerimaan SPP S1 reguler sebelum dan sesudah kebijakan UKT. Hipotesis dalam penelitian ini adalah sebagai berikut :

H.0 : Tidak terdapat perbedaan total penerimaan SPP sebelum dan sesudah kebijakan UKT

H1 : Terdapat perbedaan total penerimaan SPP sebelum dan sesudah Uang Kuliah Tunggal.

\section{Teknik Pengumpulan Data}

Teknik pengumpulan data merupakan salah satu hal yang sangat penting bagi sebuah penelitian sehingga data yang diperoleh benar-benar sesuai dengan judul yang ditentukan. Seperti yang diungkapkan oleh Sugiono bahwa teknik pengumpulan data dapat dilakukan dengan observasi (pengamatan). Wawancara, kuesioner (angket), dokumentasi dan gabungan dari keempatnya. ${ }^{11}$

\section{Teknik Analisis Data}

Analisis data adalah rangkaian kegiatan penelaahan, pengelompokan sistematisasi penafsiran dan verifikasi data agar semua fenomena memiliki nilai sosial dan akademik ilmiah analisis dan data untuk penelitian kualitatif dimulai sudah sejak dilapangan melalui tahapan sebagaimana dikemukakan Miles dan Hubberman ${ }^{12}$ bahwa aktivitas aktivitas analisi data, yaitu data reduction, data display, dan conclusion drawing/verification ${ }^{13}$

${ }^{11}$ Sugiyono, Metode Penelitian Kombinasi (Mixed Methods), (Bandung, Alfabeta; Bandung, 2017), h. 331 s.d 357

${ }^{12}$ Matthew B. Miles and A. Michael Huberman, Analisis Data Kuantitatif (Sumber-Sumber tentang Metode Baru) (Jakarta; Penerbit UIP, 1984), h. 6 s.d 20

${ }^{13}$ Riduan, Skala Pengukuran Variabel-Variabel penelitian, (Alfhabeta; Bandung, 2002), h. 24 


\section{Pembahasan}

\section{Analisis Arus Kas}

Hasil analisis arus kas pada kedua Sekolah Tinggi Agama Islam di Sulawesi Selatan yang dananya ada dua sumber yaitu APBN (Anggaran Pendapatan Belanja Negara) dan dana kas yang bersumber dari PNBP (Pendapatan Negara Bukan Pajak) yang dihimpun dari masyarakat menunjukkan bahwa dapat mencukupi kebutuhan operasional dan program utama yakni dengan kebijakan dan pengelolaan arus kas dengan mempertimbangkan kemampuan anggaran yang tersedia. Periode tahun 2012 sampai dengan Tahun 2014 sebelum berlaku Uang Kuliah Tunggal dan Biaya Kuliah Tunggal di STAIN Watampone dan STAIN ParePare dapat memenuhi kewajiban hal ini dtunjukkan dari trend kedua lembaga pada perputaran arus kasnya karena tidak terdapatnya hutang yang tertunda dari anggaran tahun sebelumnya dan dapat menggunakan anggaran sesuai penyerapannya, Demikan halnya antara tahun 2015 sampai dengan 2017 setelah berlakunya Uang Kuliah Tunggal terdapat hutang yang tidak terbayarkan ditahun tersebut atas biaya kewajiban tunjangan honor dan biaya operasional yang tidak terbayarkan, tetapi hal ini dapat diselesaikan di tahun berikutnya diawal bulan Januari setelah modal kas dari KPPN.

\section{Rasio Analisis Arus Kas}

Penelitian ini menggunakan Ratio Liquiditas yang terdiri atas Rasio Lancar (Current Ratio), Rasio Cepat (Quick Ratio) dan Rasio Kas (Cash Ratio), dimana dari hasil pengelolahan data uji terhadap ketiga ratio menunjukkan bahwa kedua lembaga pendidikan tinggi ini yaitu STAIN Watampone dan STAIN Pare-Pare dapat memenuhi kewajiban jangka pendek terhadap hutang atau kewajibannya.

Dimana pada Ratio Lancar pada kedua lembaga untuk trend sebelum Uang Kuliah Tunggal yaitu tahun 2012 sampai 2014 perputaran rata-rata diatas 100\%, ini menunjukkan bahwa terdapat kemampuan lembaga untuk menyelesaikan kewajiban jangka pendek, sementara tahun 2015 sampai 2017 setelah Uang Kuliah Tunggal diatas ratio $100 \%$, walau tahun 2016 penurunan ratio tetapi diatas $100 \%$ hal ini disebabkan adanya beban terutang yang harus dibayarkan ketahun berikutnya atas sisa tunggakan honor.

Sementara Rasio Cepat untuk melihat besarnya alat liquid yang paling cepat digunakan untuk melunasi hutang lancar. Pada kedua lembaga STAIN Watampone dan STAIN Pare-Pare perputaran ditahun 2012 sampai 2014 diatas 100\% dengan trend rata hal ini menunjukkan dapat menyelesaikan hutang/kewajiban dengan cepat atas anggaran kas yang tersedia baik bersumber dari PNBP maupun APBN sementara untuk tahun 2016 sampai dengan 2017, terdapat nilai fluktuatif (kenaikan tahun 2016 dan mengalami penurunan ditahun 2017) disebabkan adanya beban tertunggak pada hutang atas biaya kewajiban honor dan operasional tetapi dapat diselesaikan ditahun berikutnya pada awal januari ditahun berjalan.

Rasio Kas pada kedua lembaga pendidikan ini perputaran diatas $100 \%$ karena mampu menyelesaikan hutangnya dimana aktiva kas yang bisa segera menjadi uang dalam hal ini adalah Hutang yang dibebankan oleh KPPN untuk pada akhir tahun sebagai uang muka untuk pencairan pada pembayaran yang dibebankan baik itu kategori LS atau GU seperti Honor, Pembayaran Operasional, dan lain-lain. 


\section{Analisis Uji t terhadap penerimaan dan penggunaan sebelum dan sesudah Uang Kuliah Tunggal dan Biaya Kuliah Tunggal}

Analisis untuk membandingkan penerimaan sebelum dan sesudah Uang Kuliah Tunggal Sekolah Tinggi Agama Islam di Sulawesi Selatan, maka diambil dianalisis bahwa terdapat perbedaan rata-rata signifikan untuk variabel dimana rata-rata nilai yang tinggi pada sebelum Uang Kuliah Tunggal, maka dapat disimpulkan bahwa sistim penerimaan sebelum Uang Kuliah Tunggal dapat meningkatkan pendapatan lembaga karena terdapatnya jenisjenis biaya penarikan dibandingkan setelah Uang Kuliah Tunggal sehingga perlu dalam penetapan biaya penarikan setelah Uang Kuliah Tunggal harus memperhitungkan beban anggaran. Pada penggunaan menunjukkan bahwa lebih besar sebelum Uang Kuliah Tunggal lebih tinggi, ini disebabkan pada realisasi anggaran.

\section{Simpulan}

Berdasarkan analisis arus kas dengan menggunakan rasio liquiditas sebelum dan sesudah Uang Kuliah Tunggal dan Biaya Kuliah Tunggal pada STAIN Watampone dan STAIN Pare-Pare memiliki kas liquid artinya kedua perguruan tinggi mampu untuk melunasi kewajiban jangka pendek dan dapat menjalankan program, namun untuk tiga tahun terakhir antara tahun 2015 sampai dengan 2017 terdapat beban terhutang namun hal tersebut tidak mengurangi kas sehingga biaya beban lembaga dapat diselesaikan pada tahun berikutnya.

Uji t terhadap total penerimaan SPP mahasiwa keseluruhan mulai tahun 2012 hingga tahun 2014 sebelum dan sesudah UKT berbeda nyata. Artinya setelah UKT penurunan terjadi pada penerimaan SPP satu tahun pertama karena pada saat sebelum UKT pada tahun pertama terdapat komponen lain sebagai pendapatan, sedangkan setelah biaya pendidikan dibagi merata ke dalam delapan semester menurun tetapi mengalami peningkatan atau tidak menurun.

\section{Daftar Pustaka}

Agus Sartono, Manajemen Keuangan Teori dan Aplikasi, Edisi Ketiga, Penerbit BPFE, Yogyakarta, 2010

Ahmadi Ruslam, 2005. Memahami Metodologi Penelitian Kualitatif, UM, Press Malang

Arikunto dan Suharsimi, 1993, Prosedur Penelitian Suatu Pendekatan Praktek, Cetakan Sembilan, Penerbit Rineka Cipta, Jakarta

Brigham Houston, Dasar-Dasar Manajemen Keuangan (Essential Of Financial Management), Penerbit Salemba Empat Jakarta

Darsono, dan Ashari 2005, Pedoman Praktis Memahami Laporan Keuangan, Andi Offset. Yogyakarta

Gunawan, A \& Marwan A. (2012), Anggaran Perusahaan, Edisi keenam, Penerbit BPFE Yogyakarta 
Hanafi, Mamduh M. 2007. Analisis Laporan Keuangan. Edisi Ketiga. UPP STIM YKPN. Jakarta -2008, Manajemen Keungan Internasional, Penerbit BPFE Yogyakarta

Harahap 2009. Manajemen Keuangan Satu, Cetakan Pertama. Penerbit Bina Rupa Aksara, Jakarta

Husnan Suad (2014), Dasar-Dasar Manajemen Keuangan, Penerbit Liberty, Yogyakarta Akuntabilitas Publik, Penerbit Salemba Jakarta

Kasmir, 2011. Analisis Laporan Keuangan. Edisi Revisi. Penerbit Rajawali Pers, Jakarta

--------, 2017, Pengantar Manajemen Keuangan, Cetakan Enam, Penerbit Kencana, Jakarta

Mamduh M. Hanafi, Manajemen Keuangan, Cetakan kedelapan, Penerbit BPFE, Yogyakarta

Munawir, 2002 Analisis Laporan Keuangan, BPFE Yogkarta

Martono, D. Agus Harjito, 2014, Manajemen Keuangan, Cetakan IV, penerbit Econsia Jogjakarta

Riduan, 2002, Skala Pengukuran Variabel-Variabel Penelitian, Penerbit Alfhabeta, Bandung Jawa Barat

Riyanto Bambang, Pembelajaran Perusahaan, BPFE, Yogyakarta 2016

Sartono, Agus, Manajemen Keuangan, BPFE, Yogyakarta, 2003

Sawir, Agnes (2005), Analisis Kinerja Keuangan dan Perencanaan Keuangan Perusahaan, Cetakan kelima Penerbit Gramedi Pustaka Utama Jakarta

Standar Satuan Biaya Operasional Perguruan Tinggi, Direktur Jenderal Pendidikan Tinggi Kementeian Pendidikan dan Kebudayaan 2014

Sugiyono, 2011, Metode Penelitian Kombinasi (Mixed Methods), penerbit Alfabeta, Bandung

Winda Rosiana Pratiwi, 2014 Pengaruh Pendidikan, Pengalaman, dan Faktor Sosail Terhadap Pemanfaatan Informasi Laporan Arus Kas (Studi Empiris pada Instansi Pemerintah di Jawa Tengah) Diponegoro Journal of Accounting. 